\title{
Tabellarische Zusammenstellung der Rohrweiten für ver- schiedene Zirkulationshöhen und horizontale Entfiernungen bei Warmwasserheizungen mit unterer Wasserverteilung
}

\author{
Bearbeitet nach den Recknagelschen Hilfstabellen \\ von \\ Ernst Haase, Ingenieur
}

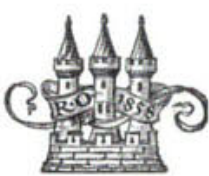

München und Berlin

Druck und Verlag von R. Oldenbourg 1911 
Alle Rechte, insbesondere das der Ubersetzung in andere Sprachen, varbehalten. 